\title{
Ovarian Primitive Germ Cell Tumor
}

National Cancer Institute

\section{Source}

National Cancer Institute. Ovarian Primitive Germ Cell Tumor. NCI Thesaurus. Code C39986.

A malignant tumor that arises from the ovary and is characterized by the presence of malignant germ cell components but lacks a teratoma component. 